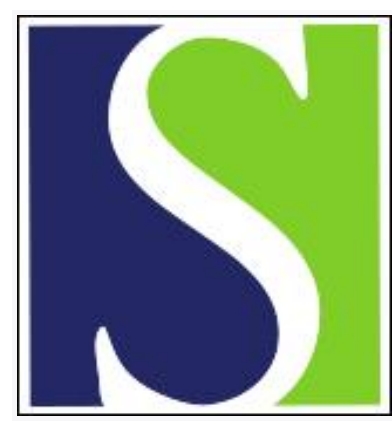

Scand J Work Environ Health 2001;27(1):21-29

https://doi.org/10.5271/sjweh.583

Issue date: Feb 2001

Physical exposure assessment in monotonous repetitive work - the PRIM study

by Fallentin N, Juul-Kristensen B, Mikkelsen S, Andersen JH, Bonde JP, Frost $\mathrm{P}$, Endahl L

Affiliation: National Institute of Occupational Health, Department of Physiology, Lersø Parkallé 105, DK 2100 Copenhagen, Denmark. nf@ami.dk

Refers to the following texts of the Journal: 1996;22(2):94-101 1995;21(3):215-222

The following article refers to this text: 2003;29(5):354-362

Key terms: between-group variance; homogeneous exposure groups; misclassification; occupational epidemiology; work-related musculoskeletal disorder

This article in PubMed: www.ncbi.nlm.nih.gov/pubmed/11266143

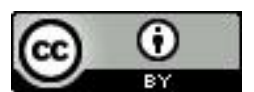




\title{
Physical exposure assessment in monotonous repetitive work — the PRIM study
}

\author{
by Nils Fallentin, PhD, ${ }^{1}$ Birgit Juul-Kristensen, ${ }^{1}$ Sigurd Mikkelsen, MD, ${ }^{2}$ Johan Hiid Andersen, MD, ${ }^{3}$ \\ Jens Peter Bonde, MD, ${ }^{4}$ Poul Frost, MD, ${ }^{3,4}$ Lars Endahl, MSc ${ }^{1}$
}

\begin{abstract}
Fallentin N, Juul-Kristensen B, Mikkelsen S, Andersen JH, Bonde JP, Frost P, Endahl L. Physical exposure assessment in monotonous repetitive work - the PRIM study. Scand J Work Environ Health 2001;27(1): $21-29$.
\end{abstract}

Objectives A program called the Project on Research and Intervention in Monotonous Work (PRIM) was initiated in 1994 as a prospective cohort study of work-related musculoskeletal disorders. The group-based exposure assessment strategy, focusing on task-related exposure and used to obtain baseline measures of physical exposures, is reported in this paper.

Methods Monotonous, repetitive worktasks were evaluated at 19 factories. Tasks with an estimated similarity in physical exposure were aggregated before 103 exposure groups were formed. Subjects from the exposure groups were randomly sampled for measurements, and task-related exposure levels were quantified by 43 single exposure items using a real-time video-based observation method that allowed computerized estimates of repetitiveness, body postures, force, and velocity. In combination with questionnaire-based data on task distribution, the duration of exposure was calculated at the individual level.

Results The video-based observational method and the large number of exposure variables enabled the establishment of detailed quantitative exposure profiles in 103 task-based exposure groups. However, methodological problems associated with the use of grouped exposure assessment were revealed. Despite efforts to optimize group homogeneity, the within-group variance was larger than the between-group variance for several shoulder postural variables.

Conclusions A task-based exposure-assessment strategy can be successful in solving some of the main problems associated with the assessment of physical workplace exposures. The large within-group variance in exposure to nonneutral shoulder postures may eventually require individual assessment or the inclusion of groups with maximal contrast in exposure or both.

Key terms between-group variance, homogeneous exposure groups, misclassification, occupational epidemiology, work-related musculoskeletal disorders.

During the last decade, work-related musculoskeletal disorders have been the dominant category of registered occupational and work-related diseases in several $\mathrm{Eu}-$ ropean countries (1). For the individual worker the result can be long-term pain and functional impairment. For society, the costs associated with the disorders are huge. In Denmark alone, estimates point to an annual expenditure of DKK 7.5 billion for work-related musculoskeletal disorders corresponding to $1 \%$ of the
Danish gross national product (2). Consequently, numerous preventive efforts have been launched to counteract this development.

In the fall of 1993, the Danish government initiated an ambitious concerted action. The aim was to reduce the number of repetitive monotonous jobs involving a risk of musculoskeletal disorders by half before the year 2000 . The concerted action incorporated several preventive strategies mainly focusing on mandatory changes

1 National Institute of Occupational Health, Copenhagen, Denmark.

2 Department of Occupational Medicine, Copenhagen County Hospital, Glostrup, Denmark.

3 Department of Occupational Medicine, Herning Hospital, Herning, Denmark.

4 Department of Occupational Medicine, Aarhus University Hospital, Aarhus, Denmark.

Reprint requests to: Dr Nils Fallentin, National Institute of Occupational Health, Department of Physiology, Lersø Parkallé 105, DK 2100 Copenhagen, Denmark. [E-mail: nf@ami.dk] 
in work organization and production systems in highrisk trades and factories. In response to the need for more specific guidelines and quantitative estimates of workplace risk factors, a research program called PRIM (Project on Research and Intervention in Monotonous work) was established by the Danish Working Environment Fund and the Danish Medical Research Council.

A key concern in the PRIM program - and the Achilles heel of many previous epidemiologic studies of work-related musculoskeletal disorders - has been the validity of physical exposure assessment. The focus on exposure assessment as the cornerstone of risk analysis is not surprising since a valid exposure assessment is a prerequisite for the establishment of exposureeffect relationships and an important tool with which to evaluate objectively the effect of intervention studies (3). The magnitude of unsolved problems in this area is reflected in the increasing number of international publications discussing conceptual and methodological aspects related to the assessment of physical workplace exposure $(4,5)$.

A major problem in physical exposure assessment concerns the variability in exposure between workers performing the same job and the choice of sampling strategies for maximizing precision using individual or grouped exposure assessment. This problem parallels a similar debate focusing on human exposure to industrial solvents or airborne chemicals in exposure assessment strategies in occupational and environmental epidemiology $(6,7)$.

Another more fundamental problem of physical exposure assessment relates to the insufficient hazard identification characterizing work-related musculoskeletal disorders. In a multifactorial disease, hazard identification is crucial, being the only guideline capable of assuring that the relevant exposure variables are addressed. In studies of work-related musculoskeletal disorders precise information on workplace hazards is often nonexistent or conflicting, and as a result a detailed account of relevant exposure variables to be included in a sampling strategy is difficult to give. This difficulty emphasizes that improving the quality of physical exposure assessment is more than a "technical problem" of methodology and sampling strategies. The need for research related to hazard identification, including mechanism relevance, in order to improve future exposure assessment is thus obvious.

Our paper presents the approach used in the PRIM study together with results illustrating the quantitative appearance of workplace risk factors in monotonous repetitive worktasks. The principal aim of the method was to provide baseline exposure measurements in the PRIM health study, a 4-year epidemiologic follow-up study of work-related neck and upper-limb musculoskeletal disorders.

\section{Subjects and methods}

The PRIM study population covered 3123 workers from 19 different factories representing a variety of industries ranging from food-processing (poultry and pork processing plants and bakeries) to textiles, cardboard packing, plastic and toy production, postal sorting centers, supermarkets, and work with video display units. In order to obtain measures of physical exposure in this large number of factories with a variety of job tasks, a groupbased exposure assessment strategy focusing on taskor process-related exposure was applied. Grouped exposure assessment indicates that exposure quantification is based on groups of workers estimated to have the same exposure profile. A measure of a group mean based on random samples - is assigned to each person in the group. Groups can be defined according to job title or location (eg, factory, building, and room), or a more-detailed task-based approach emphasizing the exposure in the different tasks of a given job can be used (8).

\section{Establishment of exposure groups}

In the PRIM study, task-related exposure groups were established following repeated visits to the 19 factories, extensive walk-throughs, and reviews of existing job data. All monotonous, repetitive worktasks at a given factory were evaluated. Tasks with an estimated similarity in physical exposure level (ie, comparable levels of repetitiveness, postural demands, and force requirements) were aggregated before the exposure groups were formed. On the average, 5-6 task-related exposure groups were established at each of the 19 factories, for a total of 103 exposure groups, which constituted the basic material for the exposure assessments of the study. The number of worktasks included in an exposure group varied from 1 to 18 . (A total of 300 monotonous, repetitive worktasks was evaluated, and the median number of tasks per exposure group was 2.)

Workers at the 19 factories with nonrepetitive tasks (eg, varied office work, internal transportation, and supervision) were included as an unexposed reference group, which comprised $25.2 \%$ of the cohort. A limited number of repetitive tasks was not assessed since the tasks included only a few workers. Workers engaged in these tasks, approximately $6 \%$ of the cohort, were excluded.

\section{Exposurequantification}

Data concerning the magnitude or intensity and time variation (repetitiveness) of exposure were obtained using a video-based observation method. Random samples of workers from each of the 103 exposure groups were selected for the measurements. Between 1 and 7 (median 3) workers from each exposure group were 
videotaped using 3 camera angles (rear, side and close up of the hand-wrist region). Recording time corresponded to at least 10 work cycles or a minimum period of 10-15 minutes for the exposure groups with long work cycles. In a subsequent computer-based analysis, measures of the magnitude or intensity and time variation of exposure were calculated. Values for the different exposure groups were represented by the median of the individual results from the monitored workers. Estimates of repetitiveness, body postures, force, and velocity parameters constituted 43 single exposure items.

Seven variables were used to quantify repetitiveness. One was the number of movements per minute for different joints. It represents an important variable in the exposure dimension of time variation, and guidelines suggesting threshold limit values for an acceptable number of movements have been published $(9,10)$. In order to describe a movement in the computer analysis, the methods-time measurement (MTM) system was used as reference. A sequence of MTM elements - reach $(\mathrm{R})$, grasp (G) and move-release (M-RL) - defined 1 movement (11). Two other items, duration of exertion (ratio of loaded to total cycle time) and number of exertions per minute (often synonymous with number of fundamental work cycles), were included as additional indicators of temporal variability, and they proved to be necessary supplements to information on crude cycle time.

In general, the choice of variables for work postures repeats the approach used in several other observational methods. (For reviews see references 12 and 13.) Some basic variables were used to describe work postures for the arms, wrists, and neck as the percentage of cycle time, for example, shoulder flexion $(0-30,30-$ 60 , and $>60$ degrees), shoulder extension, shoulder abduction $(0-30,30-60$, and $>60$ degrees $)$, neck flexion ( $0-20$ and $>20$ degrees), hand-wrist flexion (1545 and $>45$ degrees), hand-wrist extension ( $15-45$ and $>45$ degrees), hand-wrist radial deviation (5-15 and $>15$ degrees), and hand-wrist ulnar deviation (10-20 and $>20$ degrees). Video recordings from the side were used in the analysis of shoulder flexion-extension and neck flexion, the rear camera angles allowed the analyses of shoulder abduction, and the close ups of the handwrist region were used in the analyses of hand-wrist postures. Arm and neck postures were analyzed for all the exposure groups, while hand-wrist postures were only analyzed in the exposure groups representing handintense tasks (ie, hand-wrist movements exceeding 10/ minute).

In addition to the basic postural variables, 1 item percentage of cycle time with hands above shoulder height - was analyzed to allow a comparison with the simultaneous estimates of flexion in the shoulder joint. At the same time the basic items concerning neck posture (position of the head with respect to the line of gravity) was supplemented by an estimate of neck inclination ("tilting" of the head with respect to the normal line of gaze) as recommended in the draft standard of the International Organization for Standardization on the evaluation of work postures (14).

In an attempt to characterize further the amount of active shoulder flexion-abduction, the occurrence of micropauses was registered by computing the percentage of cycle time spent with the upper arm supported or hanging down vertically for more than 2 seconds, as suggested by Kilbom et al (15). To study the effect of the length of micropauses, an additional item changing the "filter-setting" of the time base and calculating the time spent with the upper arm supported or hanging down vertically for more than 1 second was included.

Estimates of force requirements and movement velocities for different joints constituted the last 7 exposure items. Force and velocity requirements were subjectively assessed and computed by the observer using 5 -point ordinal scales with verbal anchoring, as described by Moore \& Garg (16) . ${ }^{5}$ Briefly, peak force requirements during a work cycle were classified as light [ $<10 \%$ of the MVC (maximal voluntary contraction)], somewhat hard (10\%-29\% of the MVC), hard (30\%$49 \%$ of the MVC), very hard (50\%-79\% of the MVC), or near maximal ( $\geq 80 \%$ of the MVC). Estimates were performed separately for the shoulder joint, upper armelbow, hand-wrist, and fingers while taking into account the strength of the specific muscle groups in question and the position of the joint. Movement velocities for the shoulder, upper arm-elbow, and hand-wrist were simultaneously rated from 1 (very slow) to 5 (very fast). The intermediate ratings classified the movements as follows: 2 = slow, 3 = fair or "normal speed of motion", and $4=$ fast.

Data on duration of exposure (ie, time, in hours/day, spent in each exposure group) were provided by the workers' self-reports. Using a questionnaire constructed specifically for each of the 19 factories, the workers reported their daily work routines in terms of the hours the job tasks belonging to the different exposure groups were performed per day. The questionnaire was distributed and worked up by the regional departments of occupational medicine. With the use of the questionnaire data, it was possible to account for at least $85 \%$ of the daily worktime for each worker, and therefore we were able to give the 3123 members of the cohort their own unique time-weighted exposure profile, which illustrated the proportion of the workday spent in each exposure group. Estimates of cumulative physical 
Table 1. Intraclass correlation coefficients for the 15 exposure variables. The results are based on 20 video recordings independently analyzed by 2 observers. (MVC = maximal voluntary contraction)

\begin{tabular}{lc}
\hline Exposure variable & $\begin{array}{c}\text { Intraclass correlation } \\
\text { coefficient }\end{array}$ \\
\hline Oycle time (seconds) & 1.00 \\
Repetitive movements of shoulder \\
(number/minute) & 0.98 \\
Force levels (scale 1-5a) & \\
Shoulder & 0.70 \\
Bbow & 0.75 \\
Hand & 0.60 \\
Shoulder abduction (\% cycle time) & \\
Micropauses & 0.77 \\
$0-30$ degrees & 0.96 \\
$30-60$ degrees & 0.82 \\
$>60$ degrees & 0.95 \\
Neck flexion of $>20$ degrees (\% cycle time) & 0.91 \\
Hand-wrist ulnar-radial deviation (\% cycle time) & \\
Neutral & \\
Radial & 0.71 \\
$5-15$ degrees & \\
$>15$ degrees & 0.52 \\
Ulnar & 0.00 \\
$10-20$ degrees & 0.83 \\
$>20$ degrees & 0.34 \\
\hline a Rating criteria: $1=\sim$ light $(<10 \%$ MVC); $5=\sim$ near maximal $(>80 \%$ \\
MVC). The criteria were based on the results of Moore \& Gerg $(16)$. \\
b Interval between 5 degrees radial and 10 degrees ulnar. \\
\end{tabular}

exposure over the workday could thus be obtained by allocating the exposure assessment for the different exposure groups (based on random samples and group medians) to the proportional distribution of worktasks over the workday (based on individual questionnaires). ${ }^{6}$

\section{Method reliability}

Video recordings and subsequent computer analysis were performed by 3 trained physiotherapists. Interobserver reliability was estimated by an independent analysis of the same 20 video recordings from different job categories by 2 observers. (Fifteen representative exposure variables were selected from the 43 to ensure that the reliability test included measures of work postures, repetitiveness, and force demands.) A 2-way analysis of variance was used to compute the intraclass correlation coefficient $\left(\mathrm{r}_{\mathrm{i}}\right)$ and evaluate interobserver reliability. Excellent agreement was found for 9 of the 15 exposure variables $\left(r_{i} \geq 0.75\right)$ and fair to good agreement $\left(0.4<\mathrm{r}_{\mathrm{i}}<0.75\right)$ for 4 variables. Poor agreement $\left(\mathrm{r}_{\mathrm{i}}<0.4\right)$ was seen for 2 variables (extreme ulnar-radial deviation in the hand-wrist) with almost no occurrence in the analyzed tapes (table 1).

\section{Analysis of variance}

A group-based measurement strategy aims at establishing groups that combine a high similarity in exposure profile (homogeneity) with a clear distinction from the other exposure groups (contrast). This goal requires, in general, that the variance between the groups be larger than the variance within groups. A single number estimate of within and between group variance for the different exposure variables was obtained by computing the ratio of the mean of the standard deviations for all exposure groups (within-group standard deviation) to the standard deviation of the mean values across exposure groups (between-group standard deviation). Low ratio values $(\mathrm{Q})$ indicate that the between-group variance is the prime source of exposure variance. The components of the between- and within-group variance have, in previous studies, been estimated by means of a nested 2way analysis of variance $(17,18)$. In this model, however, the assumption is that the group factor is treated as a random effect. In the PRIM study, the establishment of exposure groups was based on the assumption that levels of exposure differed significantly between the groups and the nested approach could therefore not be applied.

\section{Results}

\section{General exposure profile}

The frequency and intensity of the generic risk factors associated with work-related musculoskeletal disorders with respect to monotonous, repetitive worktasks can be estimated by pooling the results from all the exposure groups studied. The results are presented in table 2 . Shoulder, upper arm, or wrist movements at levels exceeding suggested exposure guidelines for acceptable levels of repetition (9) were seen in a very high proportion of the 103 exposure groups. Shoulder movements exceeded the recommended level of 2.5 movements/ minute in $98 \%$ of the exposure groups, while suggested threshold limit values for upper arm and hand-wrist movements (10 movements/minute) were exceeded in $78 \%$ and $75 \%$ of the exposure groups, respectively. At the same time, high force demands - force demands exceeding scale values of 2 (corresponding to $29 \%$ of the MVC) - were present in 28\% (hand-wrist region) or $20 \%$ (shoulder) of the exposure groups.

In general, the exposure profile indicates a high level of exposure to physical workplace risk factors in the

6 Our paper focuses on baseline exposure data only. In the PRIM study design, however, exposure trends (varying exposure over time) were carefully monitored throughout the follow-up period. New worktasks or major changes in technology or work organization was assessed using the exposure assessment method described in this paper, while individual changes in daily worktasks were tracked by repeated administrations of the job-task questionnaire. 
exposed part of the cohort. However, adverse postural demands in the shoulder region seemed modest. The frequently cited border of acceptability for shoulder postures of 60 degrees of flexion $(19,20)$ was almost never exceeded in the PRIM exposure groups.

\section{Methodological considerations}

Variance between and within exposure groups. Large exposure gradients were seen between the exposure groups at different factories or in different industrial sectors. Table 3 illustrates these differences by presenting exposure variables from the dominant exposure group (with respect to man-hours or number of employees) in 3 PRIM factories exhibiting different levels of exposure. Poultry processing was characterized by high repetitiveness (short cycle time, extreme number of repetitive movements), awkward work postures for several body regions, and use of high force levels, especially in the hand-wrist region (cutting task). The cardboard factory presented a different exposure profile with lower repetitiveness, moderate duration of exertion, and a limited number of awkward work postures, but relatively high force levels due to manual materials handling. Finally, the dominant exposure group at the electronic plant combined long formal cycle times, a high repetition rate in the hand-wrist region, high duration of exertion, and an extreme percentage of awkward or constrained work postures (almost constant neck flexion due to visual requirements) with very modest force requirements.

At the same time, marked differences in exposure levels could be observed between the exposure groups at the same factory. Table 4 presents a typical example of large exposure gradients between 2 exposure groups at a cardboard factory. The dominant exposure group in the cardboard factory production line included in table 3 is compared with another exposure group at the same production line in table 4. This exposure group, labeled "high repetitive feeding", completely differed from the moderate levels of repetitiveness and awkward work postures seen in the dominant exposure group and exhibited levels equal to or exceeding those of the poultry processing plant. Force requirements, on the other hand, were significantly lower.

The within-group variability is illustrated by the range of values for the individual observations included in tables 3 and 4. Despite the marked differences and unique characteristics of the different exposure groups when group median values were compared, a considerable degree of overlapping is indicated for several postural variables.

Table 2. Characteristics (frequency and intensity) of selected generic risk factors associated with work-related musculoskeletal disorders in the 103 exposure groups (exposed part of the cohort). (MVC = maximal voluntary contraction)

\begin{tabular}{lrr}
\hline Exposure variable & Median & \multicolumn{1}{l}{$\begin{array}{l}\text { Interquartile } \\
\text { range }\end{array}$} \\
\hline Repetition & & \\
$\quad$ Oycle time (seconds) & 20.6 & $7.5-77.7$ \\
$\quad$ Shoulder movements (number/minute) & 16.0 & $11.8-21.0$ \\
$\quad$ Hand/wrist movements (number/minute) & 15.0 & $10.0-22.0$ \\
$\quad$ घbow movements (number/minute) & 14.5 & $11.0-21.5$ \\
Awkward work postures (\% of cycle time) & & \\
$\quad$ Shoulder flexion $>30$ degrees & 20.1 & $9.5-30.6$ \\
$\quad$ Shoulder abduction $>30$ degrees & 12.5 & $4.4-23.6$ \\
$\quad$ Shoulder flexion $>60$ degrees & 0.7 & $0.0-4.6$ \\
$\quad$ Neck flexion $>20$ degrees & 86.9 & $63.4-96.6$ \\
$\quad$ Wrist ulnar deviation ${ }^{\mathrm{a}}>10$ degrees & 13.7 & $5.9-26.7$ \\
Force levels (scale $1-5^{b}$ ) & & \\
$\quad$ Shoulder & 1.5 & $1.0-2.0$ \\
$\quad$ Hand-wrist & 2.0 & $1.0-2.5$ \\
\hline
\end{tabular}

a Only calculated for exposure groups with hand-intense worktasks $(\mathrm{N}=88)$.

b Rating criteria: $1=\sim$ light $(<10 \%$ MVC); $5=\sim$ near maximal $(>80 \%$ MVC). The criteria were based on the results of Moore \& Garg (16).

Table 3. Exposure variables representing the dominant exposure group category in 3 of the factories studied. $(\mathrm{N}=$ number of workers monitored per exposure group, $\mathrm{MVC}=$ maximal voluntary contraction)

\begin{tabular}{|c|c|c|c|c|c|c|}
\hline \multirow[t]{2}{*}{ Selected exposure variables } & \multicolumn{2}{|c|}{ Poultry processing plant ${ }^{\mathrm{a}}$} & \multicolumn{2}{|c|}{ Cardboard factory ${ }^{\mathrm{b}}$} & \multicolumn{2}{|c|}{ Bectronic plant ${ }^{c}$} \\
\hline & Median & Range & Median & Range & Median & Range \\
\hline Oycle time (seconds) & 2.8 & $2.6-2.8$ & 19.9 & $10.2-32.7$ & 1050.0 & $600.0-1800.0$ \\
\hline Duration of exertion ( $\%$ cycle time) & 87.9 & $82.6-91.0$ & 62.0 & $44.0-90.0$ & 97.5 & $97.0-98.0$ \\
\hline \multicolumn{7}{|l|}{ Repetitive movements (number/minute) } \\
\hline $\begin{array}{l}\text { Shoulder } \\
\text { Hand-wrist }\end{array}$ & $\begin{array}{l}32.0 \\
32.0\end{array}$ & $\begin{array}{l}22.0-46.0 \\
22.0-46.0\end{array}$ & $\begin{array}{l}7.2 \\
7.2\end{array}$ & $\begin{array}{l}4.3-12.4 \\
4.3-12.4\end{array}$ & $\begin{array}{r}2.0 \\
23.5\end{array}$ & $\begin{array}{l}2.0-5.0 \\
6.0-30.0\end{array}$ \\
\hline Shoulder flexion of $30-60$ degrees ( $\%$ cycle time) & 16.1 & $0.0-34.7$ & 5.1 & $0.0-10.3$ & 0.3 & $0.0-3.1$ \\
\hline Shoulder abduction of $30-60$ degrees (\% cycle time) & 0.5 & $0.0-41.4$ & 7.8 & $1.4-17.9$ & 13.9 & $2.8-17.5$ \\
\hline Neck flexion of >20 degrees (\% cycle time) & 88.6 & $81.1-96.5$ & 21.7 & $0.0-41.0$ & 97.8 & $90.8-99.1$ \\
\hline \multicolumn{7}{|l|}{ Force levels (scale $1-5^{d}$ ) } \\
\hline $\begin{array}{l}\text { Shoulder } \\
\text { Hand-wrist }\end{array}$ & $\begin{array}{l}2.5 \\
3.0\end{array}$ & $\begin{array}{l}2.5-2.5 \\
3.0-3.0\end{array}$ & $\begin{array}{l}2.5 \\
2.5\end{array}$ & $\begin{array}{l}1.0-2.5 \\
1.0-2.5\end{array}$ & $\begin{array}{l}1.0 \\
1.5\end{array}$ & $\begin{array}{l}1.0-1.0 \\
1.0-2.0\end{array}$ \\
\hline
\end{tabular}

a Job category "cutting" ( $\mathrm{N}=4)$.

b Job category "feeding" (folder-gluer) ( $N=7)$.

c Job category "assembly work" ( $\mathrm{N}=4)$.

${ }^{d}$ Rating criteria: $1=\sim$ light $(<10 \% \mathrm{MVC}) ; 5=\sim$ near maximal $(>80 \% \mathrm{MVC})$. The criteria were based on the results of Moore \& Garg (16). 
Table 4. Exposure variables representing 2 of the exposure groups at the same factory. $(\mathrm{N}=$ number of workers monitored per exposure group, $\mathrm{MVC}=$ maximal voluntary contraction)

\begin{tabular}{|c|c|c|c|c|}
\hline \multirow[t]{3}{*}{ Selected exposure variables } & \multicolumn{4}{|c|}{ Cardboard factory } \\
\hline & \multicolumn{2}{|c|}{$\begin{array}{l}\text { Job category "High repetitive feeding" } \\
\text { (folder-gluer) ( } \mathrm{N}=2 \text { ) }\end{array}$} & \multicolumn{2}{|c|}{$\begin{array}{l}\text { Job category "Feeding" (folder-gluer) } \\
(\mathrm{N}=7)\end{array}$} \\
\hline & Median & Range & Median & Range \\
\hline Oycle time (seconds) & 4.4 & $3.4-5.4$ & 19.9 & $10.2-32.7$ \\
\hline Duration of exertion (\% cycle time) & 93.5 & $91.5-95.4$ & 62.0 & $44.0-90.0$ \\
\hline \multicolumn{5}{|l|}{ Repetitive movements (number/minute) } \\
\hline $\begin{array}{l}\text { Shoulder } \\
\text { Hand-wrist }\end{array}$ & $\begin{array}{l}34.3 \\
34.3\end{array}$ & $\begin{array}{l}33.3-35.3 \\
33.3-35.3\end{array}$ & $\begin{array}{l}7.2 \\
7.2\end{array}$ & $\begin{array}{l}4.3-12.4 \\
4.3-12.4\end{array}$ \\
\hline Shoulder flexion of $30-60$ degrees ( $\%$ cycle time) & 40.7 & $21.4-59.9$ & 5.1 & $0.0-10.3$ \\
\hline Shoulder abduction of 30-60 degrees (\% cycle time) & 51.2 & $34.6-67.8$ & 7.8 & $1.4-17.9$ \\
\hline Neck flexion of >20 degrees (\% cycle time) & 84.9 & $72.2-97.5$ & 21.7 & $0.0-41.0$ \\
\hline \multicolumn{5}{|l|}{ Force levels (scale $1-5^{a}$ ) } \\
\hline $\begin{array}{l}\text { Shoulder } \\
\text { Hand/wrist }\end{array}$ & $\begin{array}{l}1.5 \\
1.5\end{array}$ & $\begin{array}{l}1.5-1.5 \\
1.5-1.5\end{array}$ & $\begin{array}{l}2.5 \\
2.5\end{array}$ & $\begin{array}{l}1.0-2.5 \\
1.0-2.5\end{array}$ \\
\hline
\end{tabular}

a Rating criteria: $1=\sim$ light $(<10 \%$ MVC); $5=\sim$ near maximal ( $>80 \%$ MVC). The criteria were based on the results of Moore \& Garg (16).

In table 5, the $\mathrm{Q}$ ratio is presented as a crude measure to indicate the relative importance of within- and between-group variance. In the comparison of occupational groups in epidemiologic studies the betweengroup variance should be the most important source of exposure variability $(17,18)$. This was the case for exposure variables linked to work organizational procedures (ie, cycle time, number of exertions per minute, duration of exertion, micropauses), force requirements, and some work postures (eg, ulnar deviation of the hand-wrist). Problems could, on the other hand, be seen for some of the variables primarily related to shoulder postures, for which within-group variance was relatively higher (reflected in the high ratio values). As a consequence, exposure variables with ratios exceeding an arbitrary chosen "cut point" of $\mathrm{Q}=0.75$ — shaded area of the table - were excluded from subsequent analyses in the PRIM project.

Choice of exposure variables. When analyzed in detail, the apparently identical exposure profiles occasionally exhibited subtle differences. When median exposure levels during sewing machine work were compared with the general level of exposure in all the exposure groups in the PRIM study, using only a few crude exposure variables, the differences in exposure appeared to be marginal. Cycle time, number of repetitive movements (shoulder and hand-wrist region) and the amount of shoulder flexion ( $>30$ degrees) were almost identical in the 2 groups, while force demands were somewhat lower during the sewing machine work.

However, the inclusion of additional exposure variables (presented in table 6) clearly demonstrated that the variables related to static muscle load were at high levels among the sewing machine operators, and they exceeded the median level in all the PRIM exposure groups. Static load is a well-established risk factor, and these subtle differences indicate the importance of identifying the relevant exposure variables or agents. In this respect, the methodological benefits of including a large number of exposure variables - if a higher discrimination of health risk is intended - appear to be evident.

\section{Discussion}

The applicability of a method for assessing physical exposure depends on the ability of the method to quantify risk factors believed to cause work-related musculoskeletal disorders (12). The methodology and design used in our study seem to represent a useful approach. The video-based observational method and the large number of exposure variables analyzed enabled the establishment of specific exposure profiles and the quantification of potential occupational health hazards in 103 taskbased exposure groups. The possibility of combining task-related exposure levels with questionnaire data on task duration at the level of the individual worker further enhanced the usability of the method.

However, several methodological problems associated with the use of grouped exposure assessment were revealed. Despite efforts to optimize group homogeneity by stratifying workers into subgroups focusing on task-related exposures, the within-group variance proved to be larger than the between-group variance for several of the shoulder postural variables. As a potential lack of exposure contrast limited the possibility to unravel specific risk factors for work-related musculoskeletal disorders, the implication is that some postural exposure variables may be difficult to assess with a grouped-based strategy. 
Table 5. Ratio $(\mathrm{Q})$ of the mean of the standard deviation for all the exposure groups $(\mathrm{N}=103)$ to the standard deviation of the mean value across the exposure groups. The shaded area encloses the exposure variables with ratios exceeding the arbitrary cut point of 0.75 ; these variables were excluded from subsequent analyses.

\begin{tabular}{|c|c|c|c|}
\hline Exposure variable & Mean of standard deviations & Standard deviation of mean & Qvalue \\
\hline Force, fingers (scale $1-5$ ) & 0.12 & 0.67 & 0.18 \\
\hline Velocity, hand-wrist (scale 1-5) & 0.22 & 1.08 & 0.20 \\
\hline Oycle time (seconds) & 211.28 & 958.62 & 0.22 \\
\hline Force, hand-wrist (scale 1-5) & 0.23 & 0.79 & 0.29 \\
\hline Force, shoulder (scale 1-5) & 0.21 & 0.69 & 0.30 \\
\hline Velocity, elbow (scale 1-5) & 0.22 & 0.72 & 0.31 \\
\hline Force, elbow (scale 1-5) & 0.21 & 0.67 & 0.31 \\
\hline Number of exertions/minute & 3.54 & 10.63 & 0.33 \\
\hline Velocity, shoulder (scale 1-5) & 0.23 & 0.68 & 0.34 \\
\hline Hand-wrist extreme ulnar deviation (\% cycle time) & 3.68 & 10.62 & 0.35 \\
\hline Hand-wrist flexion-extension neutral ( $\%$ cycle time) & 9.63 & 25.83 & 0.37 \\
\hline Hand-wrist extension ( $\%$ cycle time) & 9.59 & 23.80 & 0.40 \\
\hline Duration of exertion (\% cycle time) & 6.07 & 14.97 & 0.41 \\
\hline Hand-wrist radial deviation (\% cycle time) & 3.05 & 7.30 & 0.42 \\
\hline Hand-wrist ulnar-radial deviation neutral ( $\%$ cycle time) & 9.77 & 23.21 & 0.42 \\
\hline Hand-wrist extreme radial deviation ( $\%$ cycle time) & 0.24 & 0.57 & 0.42 \\
\hline Repetitive movements of fingers (number/minute) & 38.33 & 84.94 & 0.45 \\
\hline Shoulder flexion with hand above shoulder height (\% cycle time) & 1.83 & 3.57 & 0.51 \\
\hline Head "inclination" of $>85$ degrees ( $\%$ cycle time) & 0.94 & 1.79 & 0.53 \\
\hline Hand-wrist extreme flexion (\% cycle time) & 0.36 & 0.68 & 0.53 \\
\hline Micropauses in shoulder flexion (definition 2) (\% cycle time) & 7.24 & 13.66 & 0.53 \\
\hline Micropauses in shoulder abduction (definition 2) (\% cycle time) & 8.61 & 15.70 & 0.55 \\
\hline Hand-wrist extreme extension (\% cycle time) & 1.27 & 2.31 & 0.55 \\
\hline Hand-wrist ulnar deviation (\% cycle time) & 8.39 & 15.08 & 0.56 \\
\hline Micropauses in shoulder abduction (definition 1) (\% cycle time) & 9.15 & 15.99 & 0.57 \\
\hline Repetitive movements of elbow (number/minute) & 5.39 & 9.15 & 0.59 \\
\hline Micropauses in shoulder flexion (definition 1) (\% cycle time) & 8.80 & 14.01 & 0.63 \\
\hline Repetitive movements of hand (number/minute) & 5.87 & 9.25 & 0.64 \\
\hline Head "inclination" of $0-25$ degrees ( $\%$ cycle time) & 14.34 & 21.97 & 0.65 \\
\hline Repetitive movements of shoulder (number/minute) & 5.14 & 7.87 & 0.65 \\
\hline Head "inclination" of $25-85$ degrees (\% cycle time) & 14.25 & 21.80 & 0.65 \\
\hline Neck flexion of $>20$ degrees ( $\%$ cycle time) & 14.70 & 22.30 & 0.66 \\
\hline Neck flexion of $0-20$ degrees ( $\%$ cycle time) & 14.69 & 22.28 & 0.66 \\
\hline Shoulder abduction of $0-30$ degrees (using micropause definition 1) & on 1) & 18.36 & 0.76 \\
\hline \multicolumn{4}{|l|}{ Shoulder abduction of $0-30$ degrees (using micropause definition 2) } \\
\hline ( $\%$ cycle time) & 13.78 & 8.06 & 0.76 \\
\hline Shoulder abduction of $>60$ degrees ( $\%$ cycle time) & 2.66 & 3.42 & 0.78 \\
\hline Shoulder abduction of $30-60$ degrees (\% cycle time) & 10.29 & 11.95 & 0.86 \\
\hline Shoulder flexion of $>60$ degrees ( $\%$ cycle time) & 3.71 & 4.23 & 0.88 \\
\hline Shoulder extension ( $\%$ cycle time) & 5.02 & 5.60 & 0.90 \\
\hline Hand-wrist flexion ( $\%$ cycle time) & 5.17 & 5.66 & 0.91 \\
\hline Shoulder flexion of $30-60$ degrees (\% cycle time) & 11.33 & 12.35 & 0.92 \\
\hline \multicolumn{4}{|l|}{ Shoulder flexion of $0-30$ degrees (using micropause definition 2) } \\
\hline \multirow{2}{*}{\multicolumn{4}{|c|}{$\begin{array}{l}\text { (\% cycle time) } \\
\text { Shoulder flexion of } 0-30 \text { degrees (using micropause definition } 1 \text { ) }\end{array}$}} \\
\hline & & 14.61 & 1.04 \\
\hline
\end{tabular}

Table 6. Muscle load of the sewing machine operators versus that of the general exposure level.

\begin{tabular}{|c|c|c|c|c|c|}
\hline & \multicolumn{5}{|c|}{ Variables related to static muscle load } \\
\hline & \multirow{2}{*}{$\begin{array}{l}\text { Duration of exertion } \\
\text { (median \% cycle time) }\end{array}$} & \multicolumn{2}{|c|}{ Micropauses $^{a}$ (median \% of cycle time) } & \multirow{2}{*}{$\begin{array}{l}\text { Shoulder abduction }{ }^{\mathrm{b}} \\
\text { (median \% cycle time) }\end{array}$} & \multirow{2}{*}{$\begin{array}{l}\text { Neck flexion }{ }^{c} \\
\text { (median \% cycle time) }\end{array}$} \\
\hline & & Shoulder flexion & Shoulder abduction & & \\
\hline All job categories & 97.5 & 6.2 & 7.5 & 12.5 & 86.9 \\
\hline Sewing machine operators & 98.1 & 0.0 & 0.0 & 25.8 & 95.2 \\
\hline
\end{tabular}

a $>1$ second in duration.

b $>30$ degrees.

c >20 degrees.

In general, the requirement for homogeneity and contrast in comparisons of differentially exposed occupational groups constitutes an important methodologi- cal criterion. In the PRIM study, the exclusion of variables with $Q$ values exceeding 0.75 was considered necessary to reduce the within-group variance and enhance 
the exposure contrasts. The $\mathrm{Q}$ ratio mirrors the balance between homogeneity and contrast and relates to the reflections by Heederik et al (21), who believed that a certain degree of inhomogeneity can be accepted in epidemiologic studies unless the exposure groups exhibit an overlapping exposure distribution. Specific quantitative estimates of group homogeneity are, on the other hand, important to obtain because they provide an indication of the success of establishing exposure groups based on workers' task equivalence.

Rappaport (22) defined a homogeneous group as one for which the ratio of the exposures received by the 97.5 th and 2.5th percentile of workers was $\leq 2$. Because of the limited number of observations for some exposure groups, this definition could not be used in strict terms to assess homogeneity in the 103 PRIM exposure groups. However, analyses substituting the 97.5th and 2.5th percentile with maximum and minimum exposure values could be applied to give a tentative approximation of the homogeneity of the PRIM material. With this more "conservative" approach, the results indicated that, for exposure variables related to repetitiveness, force, and velocity, a very large percentage of the exposure groups could be considered homogeneously exposed. (On the average, $82 \%$ of the 103 exposure groups met the criterion suggested by Rappaport.) For the postural variables, exposures were much less uniform. Only 51\% of the exposure groups met the criterion for group homogeneity, and this finding indicates that within-group variance or group inhomogeneity contributed significantly to the high $\mathrm{Q}$ ratio determined for the shoulder postural variables.

The problems associated with the large within-group variance in exposure to nonneutral shoulder postures may in theory be solved by an improved grouping strategy and an increased number of samples (ie, the number of workers monitored per exposure group). Interestingly, random samples of $15-25$ workers have been recommended for the assessment of trunk flexion (5), while 3 samples per exposure group appeared sufficient for the assessment of, for example, maximum external moment during manual materials handling tasks (23). In the PRIM context, however, increasing the number of samples to 15-25 workers per exposure group for the postural variables would in practice approach an individual assessment strategy. It is thus likely that individual work technique and anthropometry are stronger determinants of exposure to nonneutral shoulder postures and the associated risk of work-related musculoskeletal disorders - than task characteristics or exposure group membership. It should however be noted that the grouping strategies applied in the PRIM study proved to be efficient for the majority of the exposure variables. The results from 1 PRIM factory presented in table 4 convincingly demonstrate that, for the majority of the risk factors, large exposure gradients exist between associated exposure groups at the chosen level of specificity. Using broader characteristics as the basis for classification assessments (eg, job title or factory name or even division, ie, working at the production line) would have resulted in an erroneous misclassification of exposure.

Our large number of exposure variables (43 single items) was complicated, but necessitated by the numerous risk factors characterizing the physical workplace exposure. Efforts to solve this problem by combining different exposure variables into a single estimate of cumulative exposure have been proposed (16). Combined indices are, however, dependent on validation by largescale epidemiologic studies. Currently, insufficient knowledge of true workplace hazards strongly limits our options. The potential for errors in a risk assessment procedure when precise guidance concerning the relevant exposure variables to be included is lacking was demonstrated for the sewing machine operators presented in table 6 . The current uncertainty of hazard identification necessitates that a large number of exposure variables (a fine-meshed net) be included in all exposure assessment strategies. In this view, the time-consuming and often cumbersome method that we have presented in this paper seems to reflect the options of today.

In summary, the results from our study indicate that a task-based exposure assessment strategy can be successful in solving some of the main problems associated with the assessment of physical workplace exposure. The problems associated with the large within-group variance in exposure to nonneutral shoulder postures may eventually require individual assessment or the inclusion of groups with maximal contrast in exposure or both.

\section{Acknowledgments}

This study was supported by the Danish Working Environment Fund and the Danish Medical Research Council.

\section{References}

1. Buckle P, Devereux J. Risk factors for work-related neck and upper limb musculoskeletal disorders. Bilbao: European Acency for Safety and Health at Work, 1999.

2. Kilbom $\AA$, Armstrong T, Buckle P, Fine L, Hagberg M, Haring-Sweeney M, et al. Musculoskeletal disorders: workrelated risk factors and prevention. Int $\mathrm{J}$ Occup Environ Health 1996;2:239-46.

3. Cohrssen JJ; Covello VT. Risk analysis: a guide to principles and methods for analyzing health and environmental risks. 
Washington (DC): The Council on Environmental Quality, 1989.

4. Winkel J, Mathiassen SE. Assessment of physical work load in epidemiologic studies: concepts, issues and operational considerations. Ergonomics 1994;37:979—88.

5. Burdorf A, van Riel M. Design of strategies to assess lumbar posture during work. Int J Ind Ergon 1996;18:239—49.

6. Smith RW, Sahl JD, Kelsh MA, Zalinski J. Task-based exposure assessment: analytical strategies for summarization data by occupational groups. Am Ind Hyg Assoc J 1997;58:402_12.

7. Seixas NS, Sheppard L. Maximizing accuracy and precision using individual and grouped exposure assessment. Scand J Work Environ Health 1996;22:94-101.

8. American Industrial Hygiene Association. AIHA generic exposure assessment standard. Fairfax (VA): American Industrial Hygiene Association, 1997.

9. Kilbom Å. Repetitive work of the upper extremity, part 1 guidelines for the practitioner. Int J Ind Ergon 1994;14:51-7.

10. Genaidy AM, Al-Shedi AA, Shell RL. Ergonomic risk assessment: preliminary guidelines for analysis of repetition, force and posture. J Hum Ergol 1993;22:45-55.

11. Barnes RM. Motion and time study — design and measurement of work. New York (NY): John Wiley \& Sons, 1980

12. Kilbom Å. Assessment of physical exposure in relation to work-related musculoskeletal disorders - what information can be obtained from systematic observations? Scand J Work Environ Health 1994;20:30-45.

13. Juul-Kristensen B, Fallentin N, Ekdahl C. Criteria for classification of posture in repetitive work by observation methods [review]. Int J Ind Ergon 1997;19:397-411.

14. International Organization for Standardization (ISO). Ergonomics - evaluation of working postures (committee draft). Geneva: ISO, 1995. ISO 11226.
15. Kilbom A, Persson J, Jonsson BG. Disorders of the cervicobrachial region among female workers in the electronics industry. Int J Ind Ergon 1986;1:37—47.

16. Moore JS, Garg A. The strain index: a proposed method to analyze jobs for risk of distal upper extremity disorders. Am Ind Hyg Assoc J 1995;56:443-58.

17. Burdorf A. Sources of variance in exposure to postural load on the back in occupational groups. Scand J Work Environ Health 1992;18:361-7.

18. van der Beek AJ, Kuiper JI, Dawson M, Burdorf A, Bongers PM, Frings-Dresen MHW. Sources of variance in exposure to nonneutral trunkt postures in varying work situations. Scand J Work Environ Health 1995;21:215-22.

19. Comité Europeéen de Normalisation. Safety of machinery Human physical performance, part 4: evaluation of working postures in relation to machinery. Comité Europeéen de Normalisation, 1996. prEN 1005-4.

20. Bernard BP, editor. Musculoskeletal disorders and workplace factors: a critical review of epidemiologic evidence for workrelated musculoskeletal disorders of the neck, upper extremity, and low back. Cincinnati $(\mathrm{OH})$ : US Department of Health and Human Services, National Institute for Occupational Safety and Health, 1997.

21. Heederik D, Kromhout H, Burema J. Assessment of longterm exposures to toxic substances in air. Ann Occup Hyg 1991;35(6):671-3.

22. Rappaport SM. Assessment of long-term exposures to toxic substances in air. Ann Occup Hyg 1991;35:61-121.

23. Allread WG, Marras WS, Burr, DL. Measuring trunk motions in industry: variability due to task factors, individual differences, and the amount of data collected. Ergonomics 2000; 43:691-701.

Received for publication: 17 March 2000 